\title{
WAGR syndrome and multiple exostoses in a patient with del(11)(p11.2p14.2)
}

\author{
J M McGaughran, H B Ward, D G R Evans
}

\begin{abstract}
The WAGR syndrome (Wilms' tumour, aniridia, genital anomalies, and mental retardation) is well documented to be associated with a deletion of $11 \mathrm{p} 13$. We present a patient with a $\operatorname{del}(11)($ p11.2p14.2) who as well as all the features of WAGR syndrome has multiple exostoses. We suggest that this could be a possible locus for hereditary multiple exostoses.
\end{abstract}

(f Med Genet 1995;32:823-824)

The association of Wilms' tumour, aniridia, genital anomalies, and mental retardation (WAGR) was first described by Miller et al. ${ }^{1}$ Most affected subjects have a de novo $11 \mathrm{p} 13$ deletion and study of these subjects has led to the assignment of a Wilms' tumour gene (WT1) to $11 \mathrm{p} 13$ and an autosomal dominant aniridia gene slightly distal, also within the $11 \mathrm{p} 13$ region. ${ }^{2}$ Recently it has been suggested that the occurrence of obesity in a patient with typical del(11p13) WAGR syndrome raises the possibility of a gene contiguous with the WAGR region responsible for obesity. ${ }^{3}$ We report on a young man who has all the features of WAGR syndrome as well as multiple exostoses and suggest that a further possible contiguous gene deletion within the WAGR region may be responsible for the hereditary multiple exostoses in his case.

\section{Case report}

The proband is a 26 year old man, the second child of non-consanguineous parents. $\mathrm{He}$ weighed $3700 \mathrm{~g}$ at birth at term and was initially difficult to feed. At 9 weeks of age, bilateral aniridia was diagnosed and it was noted he had two large lacunae in the left parietal region and a large fontanelle. Subsequently bilateral buphthalmos, glaucoma, and lens opacities were diagnosed. He was also noted to have hypospadias, undescended testes, and a small penis. He had some dysmorphic features with posteriorly angulated low set ears and coarse facies. His neck was noted to be short and broad. He had numerous postoperative infections and transient hypogammaglobulinaemia was diagnosed. ${ }^{4} \mathrm{He}$ developed haematuria when aged 2 years and a Wilms' tumour was removed from the upper pole of his left kidney. ${ }^{5} \mathrm{He}$ subsequently had chemotherapy and radiotherapy. At the age of 4 years he could say only a few words and a MerrillPalmer test showed a mental age of 2 years 1 month. He passed four items on the Stanford-
Binet scale at the 2 year level. When older, his right kidney was noted to be enlarged and he had further haematuria. The diagnosis of glomerulonephritis was made in the remaining kidney but he remains well and requires antihypertensive therapy.

He was also noted to have developed multiple exostoses on many of the bones. The first to be noted were on the right upper humerus and both scapulae. He subsequently was noted to have them on the long bones of his legs, the spinous process of the second lumbar vertebra, and the right posterior iliac crest. Platyspondyly, short, broad ribs, and a triradiate pelvis were also noted. Several of the exostoses have required surgical removal and in each case were confirmed histologically as being exostoses with irregular cartilage caps.

$\mathrm{He}$ is mentally retarded and requires support at home although he is able to go out with friends and attends a day centre. $\mathrm{He}$ is further restricted by his poor vision. He walks with a wide based gait. His height is $150 \mathrm{~cm}$ ( $<3 \mathrm{rd}$ centile) and his weight is $70 \mathrm{~kg}$ ( 75 th centile).

There is no family history of eye problems or exostoses. The only history of cancer in the family is that his father died recently of carcinoma of the oesophagus at the age of 61 years.

\section{Cytogenetic results}

Samples were taken for detailed chromosome analysis and to establish whether there was a deletion of the WT1 gene using FISH probes E1241 and D8190. ${ }^{\circ}$

Chromosome analysis showed an abnormal male karyotype 46,XY,del(11)(p11.2p14.2) with an interstitial deletion in the short arm of chromosome 11 (figure). Both cosmid probes for the WT1 gene were also deleted on one of the chromosome 11 homologues.

It was not possible to obtain samples for analysis from his parents.

A cell line has been established on this patient. (Contact Dr J M McGaughran, St Mary's Hospital, Hathersage Road, Manchester M13 0JH.)

\section{Discussion}

The features of WAGR syndrome were all present in our patient. $\mathrm{He}$ also had the recently described feature of obesity which was suggested to be the result of the deletion of a gene concerned with growth contiguous with the WAGR deletion. Our patient had a deletion and the presence of multiple exostoses suggests that perhaps a further contiguous gene may be involved in the deleted DNA. 

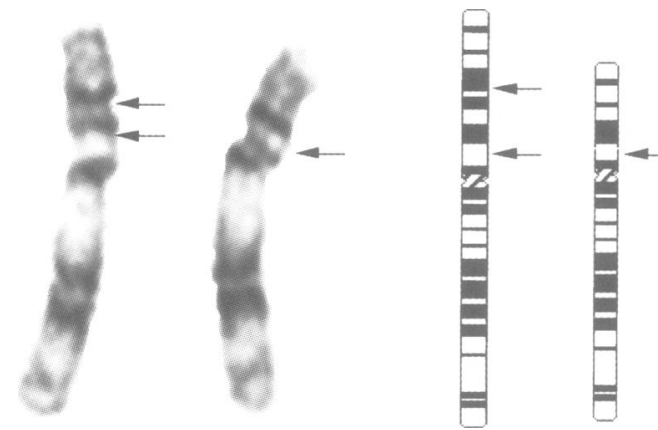

Partial karyotype of the proband. On the right is the ideogram showing the breakpoints of the deletion. On the left is the chromosome 11 pair showing the deleted chromosome.

Hereditary multiple exostoses is characterised by cartilaginous excrescences near the ends of the diaphyses of the bones of the extremities. The exostoses can give rise to complications such as compression or irritation of adjacent nerves, vessels, and tendons, and urinary and intestinal obstruction (MIM 133701). ${ }^{7}$ Reduced stature may be associated with the condition and there is a risk of sarcomatous degeneration in 0.5 to $2 \%$ of affected subjects. ${ }^{8}$

Langer-Giedion syndrome is a contiguous gene syndrome resulting from a deletion in the $8 \mathrm{q} 24$ region which has multiple exostoses as a feature. It is felt that about $70 \%$ of families with multiple exostoses show linkage to markers in the $8 \mathrm{q} 24.11-\mathrm{q} 24.13$ region. ${ }^{9}$ The candidate gene at this locus has been designated EXT1. A case of multiple exostoses with a balanced translocation $t(8 ; 11)(\mathrm{q} 24.11 ; \mathrm{p} 15.1)$ has been described $^{10}$ and it was felt that the significant breakpoint was at $8 \mathrm{q} 24.1$. Wu et al ${ }^{11}$ showed evidence of linkage to microsatellite markers from the proximal short and long arms of chromosome 11 (EXT2) in two large multiple exostoses pedigrees where linkage to markers from $8 \mathrm{q} 24$ was excluded. Le Merrer $e t a l^{12}$ tested for linkage to markers in the region 11 p12-p11 as they had a patient with multiple exostoses and an interstitial deletion of that region. Linkage to this region was excluded.
However, in 21 families that they studied they did find linkage to $19 p$ in $35 \%$. The locus was mapped to $19 \mathrm{p}$ by linkage to a microsatellite DNA marker at the D19S221 locus. The remaining $65 \%$ of the families showed linkage to chromosome 8 . This locus has been designated EXT3. No clinical differentiation could be made between the two groups of patients. In our patient, the presence of multiple exostoses could be attributed to a new mutation in any of the three putative genes described. However, the presence of a deletion involving $11 \mathrm{p} 11$ suggests that, as previously described, there may be a locus in this region of chromosome 11 and the deletion present in our patient might be able to refine further the suggested gene locus. In our patient's case, this would suggest he has a contiguous gene deletion causing his numerous problems, including his multiple exostoses for which there was no antecedent family history.

We would like to thank Dr K MacLaverty for referring the patient. We would also like to thank Mr J Dore for performing patient. FIS studies for the WT1 gene.
the

1 Miller RW, Fraumeni JF Jr, Manning MD. Association of Wilm's tumour with aniridia, hemihypertrophy and other congenital malformations. N Engl f Med 1964;270:922-7.

2 Clericuzio CL. Clinical phenotypes and Wilms tumour. Med Paediatr Oncol 1993;21:182-7.

3 Marlin S, Couet D, Lacombe D, Cessans C, Bonneau D. Obesity: a new feature of WAGR (del 11p) syndrome. Clin Dysmorphol 1994;3:255-7.

4 Evans DIK, Holzel A. Wilms aniridia syndrome with transient hypogammaglobulinemia in infancy. Arch Dis Child 1973;48:645-6.

5 Shannon RS, Mann JR, Harper E, Harnden DG, Morten JEN, Herbert A. Wilms tumour and aniridia: clinical and JEN, Herbert A. Wilms tumour and aniridia: clinical

$6 \mathrm{Kempski} \mathrm{H,} \mathrm{Cowell} \mathrm{JK.} \mathrm{Detection} \mathrm{of} \mathrm{submicroscopic} \mathrm{chro-}$ mosomal deletions in aniridia patients using fluorescence in situ hybridization and a panel of cosmids covering the WT1 gene. Int $\mathcal{F}$ Oncol 1993;3:937-40.

7 OMIM, the on-line version of Mendelian inheritance in man January 1995.

8 Hennekam RCM. Hereditary multiple exostoses. $7 \mathrm{Med}$ Genet 1991;28:262-6.

9 Cook A, Raskind W, Blanton SH, et al. Genetic heterogeneity in families with hereditary multiple exostoses. $A m$ f Hum Genet 1993;53:71-9.

10 Ogle RF, Dalzell P, Turner G, Wass D, Yip M-Y. Multiple exostoses in a patient with $\mathrm{t}(8 ; 11)(\mathrm{q} 24.11 ; \mathrm{p} 15.5) . \mathcal{F ~ M e d}$ Genet 1991;28:881-3.

11 Wu YQ, Heutink P, de Vries BBA, et al. Assignment of a second locus for multiple exostoses to the pericentromeric
region of chromosome 11 . Hum Mol Genet 1994;3:167-71.

12 Le Merrer M, Legeai-Mallet L, Jeannin PM, et al. A gene for hereditary multiple exostoses maps to chromosome 19p. Hum Mol Genet 1994;3:717-22. 